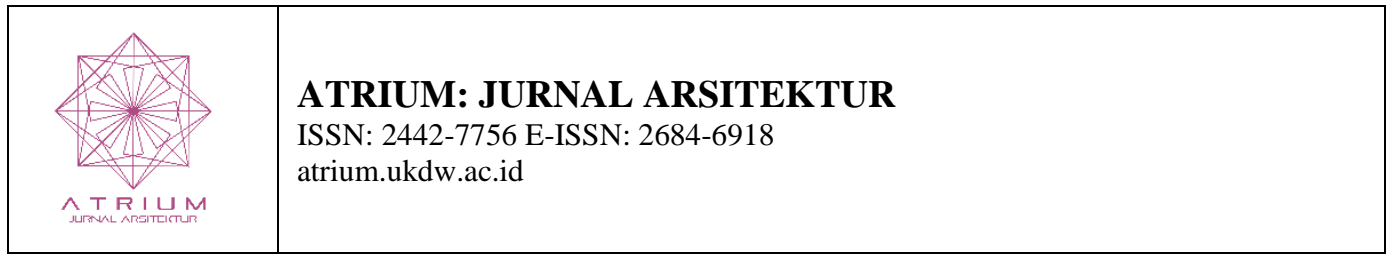

\title{
Efektivitas Daylight Mirror Shaft sebagai Sistem Pencahayaan Alami Ruang Bawah Tanah pada Langit Tropis
}

| Diterima pada 23-08-2021 | Disetujui pada 31-08-2021 | Tersedia online 30-11-2021 | | DOI https://doi.org/10.21460/atrium.v7i2.152 |

\section{Seline Adella1, Mira Dewi Pangestu ${ }^{2}$}

1,2 Program Studi Arsitektur, Fakultas Teknik, Universitas Katolik Parahyangan,

Jl. Ciumbuleuit no. 94, Bandung 40141

Email: selineadella@gmail.com

\begin{abstract}
Abstrak
Ruang bawah tanah memiliki banyak potensi untuk didayagunakan sebagai ruang fungsional, namun seringkali terabaikan karena masalah pencahayaan. Karena itu, dilakukan penelitian untuk mempelajari salah satu strategi pencahayaan ruang bawah tanah, yaitu sistem daylight mirror shaft. Sistem pencahayaan tersebut memanfaatkan penempatan bidang pantul pada sebuah light shaft untuk mengarahkan cahaya luar menuju ruang bawah tanah. Sistem daylight mirror shaft diperkenalkan oleh Heliobus $^{\circledR}$, sebuah perusahaan daylighting asal Switzerland. Untuk mengetahui kelayakan penerapan sistem tersebut di Indonesia, dilakukan studi mengenai kinerjanya pada kondisi langit tropis. Selain itu, dilakukan studi mengenai pengaruh orientasi bukaan dan penempatan light shaft terhadap tingkat iluminasi pada ruang. Data pencahayaan diperoleh melalui simulasi digital menggunakan software Lightstanza. Hasil penelitian menunjukan bahwa efektivitas penerapan prinsip daylight mirror shaft pada langit tropis mampu menerangi paling banyak $41 \%$ area ruang bawah tanah. Penggunaan bidang pantul cermin pada light shaft juga dapat meningkatkan kuantitas persebaran cahaya sebanyak 2.1 kali lipat dibandingkan shaft tanpa bidang pantul. Pada analisis lanjutan, ditemukan bahwa orientasi bukaan dan penempatan light shaft tidak berpengaruh secara signifikan terhadap kuantitas cahaya yang diperoleh. Secara keseluruhan, riset menemukan bahwa penerapan prinsip sistem daylight mirror shaft pada langit tropis masih kurang efektif, sehingga membutuhkan penyesuaian yang membutuhkan penelitian lebih lanjut.
\end{abstract}

Kata kunci: pencahayaan alami, ruang bawah tanah, daylight mirror shaft.

\section{Abstract}

Title: Effectiveness of Daylight Mirror Shafts as Natural Daylighting System for Basements under Tropic Sky Conditions

Basements have lots of potential as functional spaces, but have mostly been neglected due to lighting issues. Therefore, this study will explore the daylight mirror shaft system as a daylight strategy for basements, which features the placement of a reflecting surface on a light shaft to redirect daylight. The system was introduced by Heliobus ${ }^{\circledR}$, a daylighting company from Switzerland. To see the effectiveness of implementing the system in Indonesia, a study was made on its performance on the climate sky condition. Furthermore, a study was made on the effect of different opening orientations and light shaft placements toward the illuminance level achieved. The lighting data was obtained using the simulation softwares Lightstanza. Results show that the performance of the system on climate sky condition can provide sufficient light for $41 \%$ of a basement. The use of mirrors on the light shaft could also increase the lighting levels by 2.1 times compared to a shaft without a mirror. Moreover, it was found that different opening orientations and light shaft placements didn't give a significant effect on the lighting quantity. Overall, the study shows that the system's implementation on climate skies still require adjustments through further studies to be effective.

Keywords: daylight, underground basement, daylight mirror shaft. 


\section{Pendahuluan}

Pencahayaan alami merupakan suatu faktor yang memegang peran penting dalam perencanaan sebuah bangunan gedung. Selain membantu manusia mengenali objek visual serta melakukan aktivitas, pencahayaan alami juga menimbulkan efek psikologis melalui pembentukan suasana dan kenyamanan secara visual. Karena itu, perencanaan pencahayaan alami dapat mengambil peran dalam hal fungsional, arsitektural, dan juga psikologis (Pangestu, 2019). Belakangan ini, dengan semakin meningkatnya kesadaran mengenai permasalahan alam, lingkungan sosial dan terlebih saat pandemi ini telah banyak timbul kesadaran mengenai pentingnya pencahayaan alami, sehingga memunculkan berbagai macam strategi untuk mengoptimalkan pemanfaatannya dalam perancangan. Namun, seringkali masih ada ruang-ruang yang belum terrancang untuk mengoptimalkan penggunaan cahaya alami, salah satunya adalah ruang bawah tanah.

Sebagai ruang yang seringkali hadir sebatas sebagai penunjang, terlebih lagi karena letaknya yang berada di bawah tanah, penerangan ruang bawah tanah kebanyakan hanya diterangi oleh pencahayaan buatan. Penggunaan pencahayaan buatan memiliki banyak kekurangan dibandingkan pencahayaan alami, termasuk dalam hal-hal yang berkaitan dengan aspek psikis manusia. Dengan keadaan tanpa bukaan, pengguna ruang akan mengalami kekurangan stimulasi dan koneksi terhadap alam yang diperoleh dari view ke arah ruang luar serta pencahayaan alami, sehingga timbul perasaan yang terkungkung. Karena itu, ruang bawah tanah seringkali dikaitkan dengan kondisi yang gelap (Nessim, 2000). Namun, sebenarnya ruang bawah tanah memiliki banyak peluang untuk digunakan sebagai wadah aktivitas, terutama jika ruang dapat menerima pencahayaan alami yang mencukupi. Hal tersebut juga patut dipertimbangkan, terutama karena keadaan urbanisasi pada era ini yang mendorong penggunaan ruang semaksimal mungkin. Dalam keadaan tersebut, ruang bawah tanah dapat hadir sebagai alternatif untuk fungsi tinggal maupun komersial, sehingga dapat mengurangi penggunaan lahan permukaan (Jain, 2017).

Karena isu-isu di atas, perencanaan untuk ruang bawah tanah sebaiknya memiliki design objectives tertentu, seperti menyediakan pencahayaan alami seoptimal mungkin, sehingga pencahayaan buatan hanya hadir sebagai pelengkap dan bukan sebagai pengganti. Namun, pencahayaan alami yang diterima harus tetap dapat menyediakan tingkat iluminasi yang sesuai untuk mewadahi aktivitas, sehingga tidak hanya menghadirkan koneksi dengan ruang luar, namun dapat juga mendukung aktivitas yang berlangsung. Upaya-upaya tersebut dapat dilakukan untuk meningkatkan kualitas dan kuantitas pencahayaan alami pada ruang bawah tanah, sehingga dapat memudarkan asosiasi ruang bawah tanah dengan kegelapan (Nessim, 2000). Dengan demikian, muncul dorongan untuk mempelajari strategi-strategi memasukkan cahaya alami ke dalam ruang bawah tanah, untuk dapat memaksimalkan penggunaannya sebagai ruang yang fungsional. Salah satu strategi tersebut hadir dalam sistem daylight mirror shaft asal Switzerland, yang diperkenalkan oleh Heliobus ${ }^{\circledR}$. 
Secara singkat, daylight mirror shaft merupakan sistem pencahayaan alami yang memanfaatkan bidang pemantul berupa cermin untuk memantulkan cahaya alami menuju ruang bawah tanah. Keuntungan sistem tersebut adalah sifatnya yang pasif serta perawatan yang tidak memakan banyak biaya maupun energi (Gritsiyenko and Kasyanov, 2017). Daylight mirror shaft telah diperkenalkan dan diterapkan pada belahan dunia bagian utara, terutama di negara-negara Eropa, Amerika Serikat, serta negara-negara Arab, yang tentunya memiliki kondisi langit yang berbeda dibandingkan langit tropis di Indonesia. Maka dari itu, perlu dipelajari apakah sistem pencahayaan ini juga dapat diterapkan secara efektif pada kondisi langit tropis.

Berdasarkan pada latar belakang di atas, diambil rumusan masalah sebagai berikut:

1. Sejauh mana efektivitas penerapan sistem daylight mirror shaft pada kondisi langit tropis?

2. Bagaimana pengaruh orientasi bukaan dan penempatan light shaft terhadap efektivitas kinerja daylight mirror shaft?

Studi ini dilakukan dengan harapan dapat meningkatkan pengetahuan mengenai efektivitas penggunaan daylight mirror shaft sebagai metode memasukkan cahaya alami ke dalam ruang bawah tanah pada kondisi langit tropis, serta diharapkan dapat membuka peluang bagi penerapan sistem daylight mirror shaft ke dalam perancangan pada kondisi langit tropis, sehingga dapat memaksimalkan potensi ruang bawah tanah sebagai ruang efektif yang mampu mewadahi aktivitas secara optimal.
Adapun ruang lingkup penelitian berupa:

1. Lokasi bertempat di Kota Bandung Indonesia, dengan lokasi geografis $(-6.914864, \quad 107.609811)$, serta kondisi langit tropis.

2. Pembahasan dibatasi pada efektivitas penerapan prinsip kerja sistem daylight mirror shaft pada kondisi tropis, serta melihat pengaruh kondisi langit, orientasi bukaan, serta peletakan light shaft terhadap jumlah luas ruang yang memenuhi standar iluminasi cahaya.

Daylight Mirror Shaft sebagai Sistem Pencahayaan Ruang Bawah Tanah

Daylight mirror shaft merupakan suatu sistem pencahayaan alami yang dipopulerkan oleh Heliobus ${ }^{\circledR}$, sebuah perusahaan daylighting asal Switzerland. Sistem pencahayaan tersebut bekerja berdasarkan prinsip sebuah light pipe yang menangkap cahaya matahari dan cahaya bias dari langit (Heliobus ${ }^{\circledR}$, no date a).
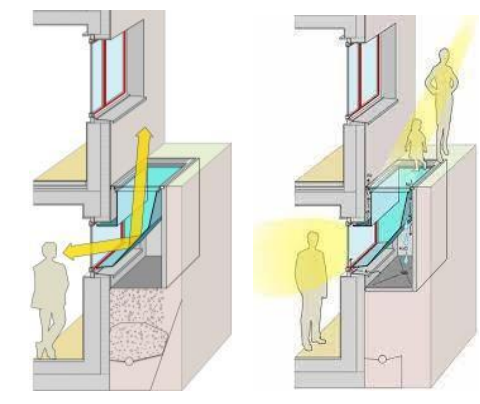

Gambar 1. Sistem daylight mirror shaft Sumber: Heliobus ${ }^{\circledR}$

Secara garis besar, prinsip sistem daylight mirror shaft memanfaatkan penempatan bidang pantul berupa cermin pada sebuah light well atau light shaft untuk dapat merefleksikan cahaya alami dari luar bangunan menuju ruang bawah tanah. Kinerja dari prinsip tersebut dapat dilihat pada simulasi pantulan cahaya di bawah, 
yang menggunakan software simulasi Ecotect Analysis 2011.

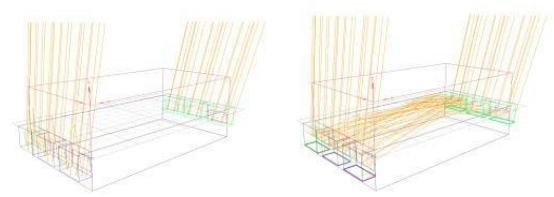

Gambar 2. Simulasi tanpa penggunaan (kiri) dan dengan penggunaan prinsip daylight mirror shaft (kanan) pada bulan September pukul 12:00

Sumber: Simulasi Ecotect, 2021

Dari hasil simulasi tersebut, terlihat bahwa dengan penambahan bidang pantul, cahaya matahari yang masuk ke dalam light shaft dapat terpantulkan ke dalam ruang melalui bukaan yang ada, sehingga mampu menerangi ruang dengan lebih efektif.

Faktor refleksi atau pemantulan itu sendiri dapat menjadi sumber cahaya alami yang memberikan pengaruh signifikan bagi iluminasi ruang (Mandala, Ritva and Gunawan, 2016). Pada daylight mirror shaft, faktor tersebut dimanfaatkan untuk mengarahkan cahaya matahari ke dalam ruang bawah tanah tanpa harus menaikkan level lantai dasar atau membuat semi-basement. Material dari bidang pantul yang digunakan juga berperan penting bagi tingkat iluminasi yang dihasilkan. Pada daylight mirror shaft, material bidang pemantul yang digunakan merupakan cermin. Cermin sendiri memiliki tingkat reflektansi yang cukup tinggi, yakni mencapai 8090\% (Lechner, 2015).

Pada penerapannya, daylight mirror shaft terbukti dapat memberikan manfaat yang signifikan bagi penerangan ruang bawah tanah. Pada gambar di bawah, terlihat kondisi ruang bawah tanah tanpa penggunaan sistem daylight mirror shaft, serta kondisi ruang yang sama ketika menggunakan sistem tersebut. Dari perbandingan antara kedua, terlihat bahwa keberadaan daylight mirror shaft mampu memberikan pengaruh yang terlihat jelas terhadap pencahayaan pada ruang bawah tanah tersebut (Heliobus ${ }^{\circledR}$, no date b).
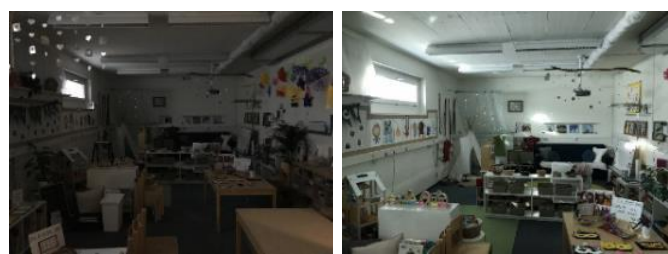

Gambar 3. Perbandingan ruang sebelum menggunakan daylight mirror shaft (kiri) dan sesudahnya (Kanan) Sumber: Heliobus ${ }^{\circledR}$

Namun, juga diketahui bahwa rasio peningkatan cahaya yang ditimbulkan tidak konstan sepanjang hari. Hal tersebut karena terkait erat dengan posisi matahari dan pembayangan, seperti dapat dilihat pada hasil studi perbedaan rasio peningkatan daylight factor pada suatu ruang, yang dapat dilihat pada grafik berikut (Guillemin, 2012).

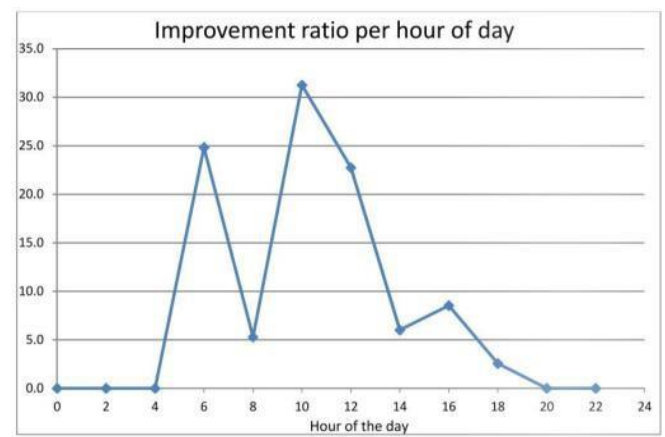

Gambar 4. Rasio peningkatan daylight factor berdasarkan jam Sumber: Guillemin, 2012

Selain itu, sebagai sistem pencahayaan alami yang berasal dari Switzerland, daylight mirror shaft kebanyakan telah diterapkan pada belahan dunia bagian utara, terutama Eropa, yang memiliki 
kondisi langit cerah (clear sky). Kondisi langit sendiri merupakan salah satu faktor yang memengaruhi kuat pencahayaan alami, serta termasuk sebagai parameter untuk perhitungan pencahayaan alami. Setiap kondisi langit yang berbeda akan memiliki variasi komponen langit yang berbedabeda (Mandala, Ritva and Gunawan, 2016). Secara umum, terdapat dua kondisi langit yang ditetapkan oleh CIE (International Illumination Commission), yakni langit cerah (clear sky) dan langit mendung (overcast sky). Sebagai tambahan, H. Nakamura dalam studinya mengusulkan kondisi langit ketiga, yaitu intermediate sky, atau langit berawan (Rahim, Baharuddin and Mulyadi, 2004). Tingkat cahaya matahari dan cahaya difus pada kondisi langit berawan dapat bervariasi sesuai dengan lokasi pengamatan. Kondisi langit yang telah disesuaikan dengan data langit pada titik lokasinya dapat juga disebut sebagai climate sky.

\section{Ketentuan dan Kriteria Daylight Mirror Shaft}

Sistem daylight mirror shaft dapat diaplikasikan pada hampir semua light shaft. Namun, terdapat kondisi-kondisi yang mempengaruhi optimasi cahaya dan view.

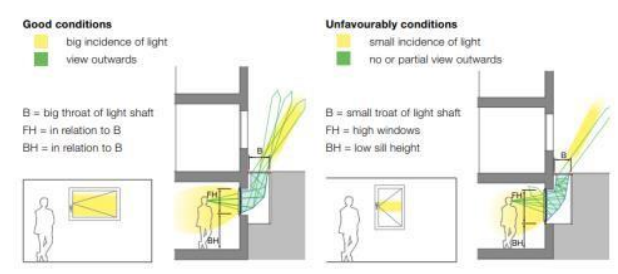

Gambar 5. Ketentuan proporsional daylight shaft

Sumber: Heliobus ${ }^{\circledR}$

Pada gambar di atas, gambar sebelah kiri menunjukkan kondisi yang baik, di mana terdapat ukuran light shaft yang ideal dan ukuran bukaan jendela yang sesuai, sehingga dapat memasukkan banyak cahaya dan menyediakan view ke luar. Sedangkan gambar di sebelah kanan menunjukkan kondisi yang kurang ideal, di mana ukuran light shaft terlalu kecil dan ukuran jendela yang tinggi, sehingga tidak dapat maksimal dalam memasukkan cahaya, serta tidak atau hanya memperoleh sedikit view ke arah luar (Heliobus ${ }^{\circledR}$, no date $b$ ).

Daylight mirror shaft juga memiliki kondisi dimensional, yang mengikuti gambar di bawah ini, berdasarkan planning aid yang disediakan oleh Heliobus ${ }^{\circledR}$.

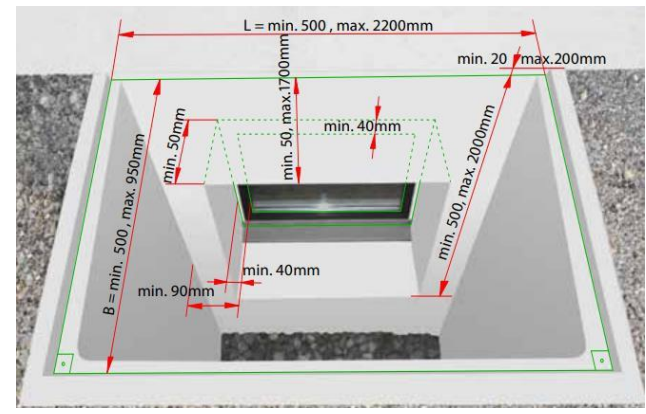

Gambar 6. Ketentuan dimensi daylight mirror shaft

Sumber: Heliobus ${ }^{\circledR}$

Untuk menentukan dimensi light shaft, parameter yang ideal antara luas ruang dan luas light shaft adalah 10:1 sampai 15:1 untuk ruang kerja dan living rooms, serta 15:1 sampai 25:1 untuk ruang penunjang. Dengan itu, rasio perbandingan antara luas A1:A2 adalah 10:1 sampai 25:1. Untuk ukuran lebar shaft (B), dapat ditentukan dimensi yang sebesar mungkin, dengan tetap mempertimbangkan kriteria lebar maksimum. Panjang shaft (L) kemudian dapat mengikuti, dari hasil luas kebutuhan shaft dibagi dengan lebarnya. 


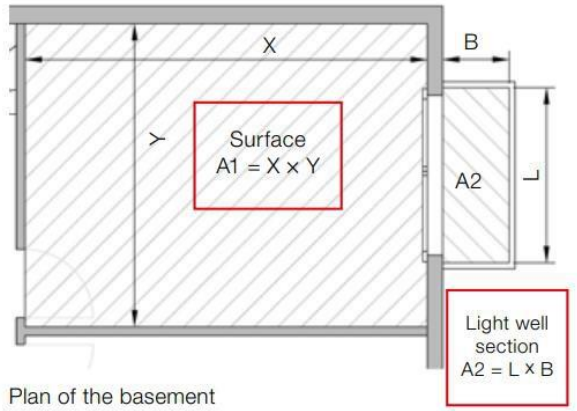

Gambar 7. Ketentuan parameter ideal luas light shaft

Sumber: Heliobus ${ }^{\circledR}$

Kemudian, untuk menentukan ketinggian bukaan dan shaft, tinggi bukaan dapat mengambil dimensi yang mendekati lebar shaft (B). Lebar bukaan (FB) dapat mengambil ukuran panjang shaft (L) dikurangi angka yang mendekati $0.2 \mathrm{~m}$, karena jarak pinggir bukaan (AB) yang ideal adalah 100mm. Untuk ketinggian bukaan ke lantai (BH), dapat diambil ukuran mendekati $1.60 \mathrm{~m}$ dikurangi dengan ukuran tinggi bukaan dibagi 3 (Heliobus ${ }^{\circledR}$, no date b).

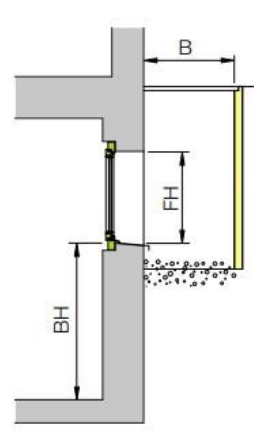

Section of light shaft

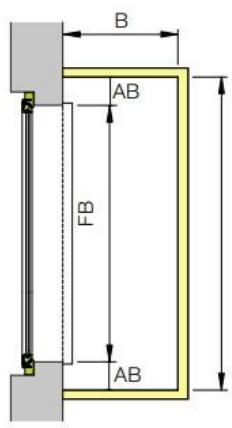

Top view light shaft
Gambar 8. Potongan dan denah light shaft Sumber: Heliobus ${ }^{\circledR}$

\section{Standar Tingkat Pencahayaan}

Pada perencanaan pencahayaan suatu ruang, penting untuk mengetahui standar-standar dan ketentuan yang berlaku, agar tingkat pencahayaan dapat memenuhi kebutuhan untuk aktivitas yang berlangsung di dalamnya. Untuk mengetahui standar pencahayaan pada sebuah ruang, diambil standar yang diperoleh dari SNI No. 03-2396-2001 tentang Tata Cara Perancangan Sistem Pencahayaan pada Bangunan Gedung, yang dapat dilihat pada tabel berikut.

Tabel 1. Rekomendasi tingkat pencahayaan minimum

\begin{tabular}{|l|c|}
\hline \multicolumn{1}{|c|}{ Fungsi Ruangan } & $\begin{array}{c}\text { Tingkat Pencahayaan } \\
\text { (Lux) }\end{array}$ \\
\hline \multicolumn{2}{|c|}{ Rumah Tinggal } \\
\hline Teras & 60 \\
\hline Ruang Tamu & $120 \sim 250$ \\
\hline Ruang Makan & $120 \sim 250$ \\
\hline Ruang Kerja & $120 \sim 250$ \\
\hline Ruang Tidur & 250 \\
\hline Ruang Mandi & 250 \\
\hline Dapur & 60 \\
\hline Garasi & 350 \\
\hline \multicolumn{2}{|c|}{} \\
\hline Ruang Direktur & 350 \\
\hline Ruang Kerja & 350 \\
\hline Ruang Komputer & 300 \\
\hline Ruang Rapat & 750 \\
\hline Ruang Gambar & 150 \\
\hline Gudang Arsip & 300 \\
\hline Ruang Arsip Aktif & \\
\hline
\end{tabular}

Sumber: Badan Standarisasi Nasional, 2001.

Berdasarkan tabel di atas, dapat dilihat bahwa untuk sebuah ruang yang fungsional dan mampu mewadahi aktivitas, tingkat pencahayaan yang ideal mencakup iluminasi pada kisaran 120-750 Lux.

\section{Metode}

\section{Jenis Penelitian}

Jenis penelitian ini adalah penelitian deskriptif-komparatif yang dilakukan dengan pendekatan kuantitatif. Data pencahayaan yang diperoleh akan bersumber dari hasil pengukuran melalui simulasi digital, yang akan dilakukan terhadap suatu objek studi. Data hasil pengukuran kemudian akan disesuaikan dengan standar iluminasi 
yang direkomendasikan oleh SNI, untuk mengetahui berapa banyak luasan ruang yang memenuhi standar tersebut.

\section{Lokasi dan Waktu Simulasi}

Penelitian akan dilakukan melalui simulasi digital, yang mengambil titik lokasi pada Kota Bandung, dengan letak geografis latitude -6.914864 dan longitude 107.609811, serta kondisi langit tropis. Simulasi pengukuran akan dilakukan pada bulan Maret, Juni, dan Desember, sebagai bulan-bulan yang mewakili posisi matahari pada ekuator, sisi Utara, dan sisi Selatan. Waktu simulasi mengambil pukul 09.00, 12.00 dan 15.00, untuk mewakili kondisi pada pagi, siang, dan sore hari.

\section{Metode Pengumpulan Data}

Untuk mendapatkan data pencahayaan, dilakukan simulasi digital pada sebuah model objek studi. Acuan standar dan ketentuan dimensi light shaft akan diperoleh melalui studi pustaka, yang dijadikan sebagai landasan pembuatan modul objek studi. Pengukuran akan dilakukan menggunakan software Lightstanza berdasarkan variabelvariabel yang telah ditentukan sebelumnya. Hasil simulasi akan menunjukkan denah dengan tingkat iluminasi dan false color pada grid titik ukur berukuran 600 milimeter. Pada modul objek studi, ukuran grid tersebut menghasilkan jumlah grid sebanyak 312 titik ukur, dengan modul $13 \times 24$ titik. Satu modul grid tersebut setara dengan luasan sebesar 0.36 meter persegi.

\section{Variabel Penelitian}

Pada studi akan digunakan objek studi berupa modul ruang bawah tanah sederhana, dengan ukuran lebar 8 meter dan panjang 15 meter, dengan ketinggian ruang 2,7 meter. Ruang bawah tanah tersebut memiliki lantai atas yang menutupi seluruh bagian ruangan. Dimensi ruang ditentukan berdasarkan ukuran tipikal bangunan dengan fungsi rumah tinggal atau kantor berukuran kecil. Modul ruang memanjang dipilih agar dapat melihat pengaruh dari peletakan light shaft pada sisi panjang dan lebar ruang. Untuk menentukan dimensi light shaft pada objek studi, digunakan parameterparameter dari design guide yang dikeluarkan oleh Heliobus ${ }^{\circledR}$.

Tabel 2. Penentuan dimensi light shaft

\begin{tabular}{|c|c|c|c|c|}
\hline $\begin{array}{c}\text { Luas } \\
\left(\mathrm{m}^{2}\right)\end{array}$ & $\begin{array}{c}\text { Parameter } \\
\text { (Rasio } \\
\text { untuk } \\
\text { Ruang } \\
\text { efektif) }\end{array}$ & $\begin{array}{c}\text { Luas } \\
\text { Total } \\
\text { Light } \\
\text { Shaft } \\
\left(\mathrm{m}^{2}\right)\end{array}$ & $\begin{array}{c}\text { Jumlah } \\
\text { Light } \\
\text { Shaft }\end{array}$ & $\begin{array}{c}\text { Luas } \\
\text { Light } \\
\text { Shaft } \\
\left(\mathrm{m}^{2}\right)\end{array}$ \\
\hline 120 & $1: 10$ & 12 & 6 & 2 \\
\hline $\begin{array}{c}\text { Panang } \\
\text { Light } \\
\text { Shaft } \\
(\mathrm{m})\end{array}$ & $\begin{array}{c}\text { Lebar } \\
\text { Light } \\
\text { Shaft } \\
\left(\mathrm{m}^{2}\right)\end{array}$ & $\begin{array}{c}\text { Lebar } \\
\text { Bukaan } \\
\left(\mathrm{m}^{2}\right)\end{array}$ & $\begin{array}{c}\text { Tinggi } \\
\text { Bukaan } \\
\left(\mathrm{m}^{2}\right)\end{array}$ & $\begin{array}{c}\text { Jarak } \\
\text { Bukaan } \\
\text { kantai } \\
(\mathrm{m})\end{array}$ \\
\hline 2.2 & 0.95 & 2 & 0.95 & 1.3 \\
\hline
\end{tabular}

Sumber: Heliobus ${ }^{\circledR}$

Dapat dilihat pada tabel di atas, untuk luas lantai objek studi yang berukuran 120 meter persegi, dibutuhkan 6 buah light shaft berukuran $2.2 \times 0.95$ meter. Masing-masing light shaft akan dilengkapi dengan bidang pemantul berupa cermin, yang dipasang dengan sudut kemiringan $45^{\circ}$.

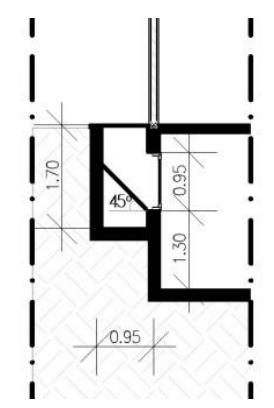

Gambar 9. Dimensi light shaft dan bukaan Sumber: Gambar kerja penulis, 2021

Variabel kontrol yang diambil pada penelitian adalah kondisi langit serta 
dimensi objek studi yang telah ditentukan sebelumnya. Penentuan dimensi tersebut mencakup dimensi modul objek studi, dimensi light shaft, jumlah light shaft, kemiringin bidang pantul, serta material bidang pantul. Untuk kondisi langit, akan digunakan kondisi langit climate sky, yakni kondisi langit yang telah disesuaikan dengan data langit pada lokasi yang disimulasikan.

Variabel bebas yang diambil adalah orientasi bukaan, baik itu UtaraSelatan atau Timur-Barat, serta peletakan light shaft, antara diletakkan pada sisi pendek atau pada sisi panjang. Berdasarkan kriteria penentuan dimensi pada design guide Heliobus $^{\circledR}$, dibuat dua jenis modul ruang, yang dapat dilihat pada gambar denah berikut.
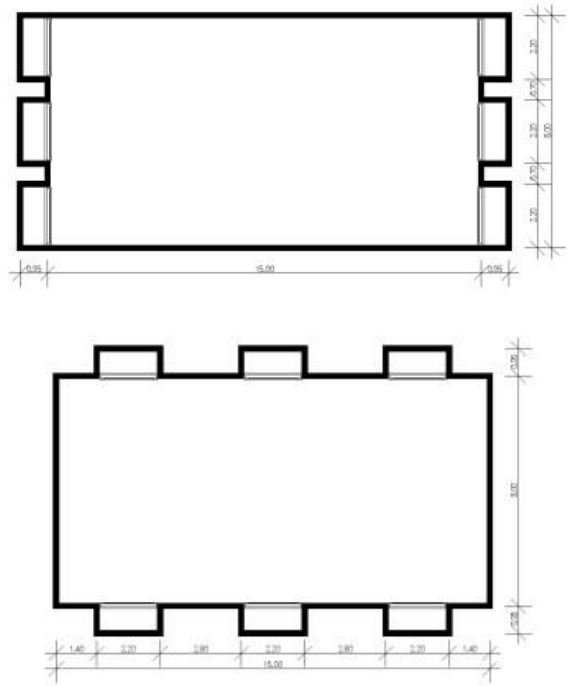

Gambar 10. Denah modul objek studi dengan shaft pada sisi lebar (atas) dan shaft pada sisi panjang ruang (bawah) Sumber: Gambar kerja penulis, 2021

Variabel terikat pada studi ini adalah kuantitas pencahayaan alami, yang diukur dengan cara melihat banyaknya jumlah iluminasi (Lux) dan jangkauan masuknya cahaya ke dalam ruang.

\section{Metode Analisis Data}

Sesudah memperoleh data melalui simulasi, akan dilakukan tahap analisis data, dengan cara membandingkan hasil besaran intensitas cahaya yang telah diperoleh antara satu sama lain. Perbandingan tersebut akan disajikan dalam bentuk tabel dan grafik.

Untuk menyederhanakan proses analisis, hasil iluminasi dan jangkauan masuknya cahaya ke dalam ruang akan ditentukan dengan cara melihat jumlah titik ukur pada modul yang memenuhi standar tingkat iluminasi untuk sebuah ruang fungsional, yaitu 120-750 Lux. Jumlah titik ukur tersebut dapat menunjukkan nilai luas ruang yang memenuhi standar iluminasi.

Analisis data akan dipisah menjadi dua bagian. Analisis pertama akan membahas mengenai perbandingan efektivitas penerapan sistem daylight mirror shaft pada kondisi langit tropis (climate sky) dengan kondisi langit cerah (clear sky) seperti pada penelitian rujukan. Kemudian, analisis kedua akan membahas mengenai pengaruh orientasi bukaan dan penempatan light shaft terhadap kuantitas cahaya pada ruang.

\section{Tahapan Penelitian}

Penelitian akan dilaksanakan melalui tahapan berikut ini:

1. Melakukan simulasi pencahayaan melalui software Lightstanza untuk mengetahui data nilai iluminasi dan jangkauan masuknya cahaya ke dalam ruang.

2. Melakukan analisis perbandingan antara kinerja daylight shaft pada langit tropis dan langit cerah melalui penyajian tabel.

3. Melakukan analisis terhadap pengaruh orientasi bukaan dan penempatan light shaft melalui penyajian tabel dan grafik. 
4. Menarik kesimpulan dan saran berdasarkan analisis yang telah dilakukan.

\section{Hasil dan Pembahasan}

\section{Analisis Efektivitas Penerapan Daylight Mirror Shaft pada Langit Tropis}

Pada analisis ini, dilakukan simulasi yang membandingkan antara efektivitas penerapan daylight mirror shaft pada langit cerah (clear sky), yakni kondisi langit pada penelitian rujukan, dengan efektivitasnya pada kondisi langit tropis (climate sky). Objek studi yang digunakan adalah modul dengan light shaft pada sisi panjang ruang, dengan keadaan tanpa dan dengan bidang pantul, agar dapat melihat efektivitas kinerja dari sistem daylight mirror shaft pada kedua kondisi langit yang ada.

Untuk menunjukkan perbandingan tersebut, akan ditampilkan hasil pengukuran yang paling optimal berdasarkan simulasi, yaitu pada bulan Maret pukul 12:00, dimana matahari berada di ekuator dan berada pada posisi tertinggi, dengan orientasi BaratTimur. Dari data simulasi, akan dicari berapa jumlah titik ukur dari keseluruhan 312 titik yang memenuhi syarat iluminasi sejumlah 120-750 Lux.

Tabel 3. Hasil simulasi perbandingan clear sky dan climate sky

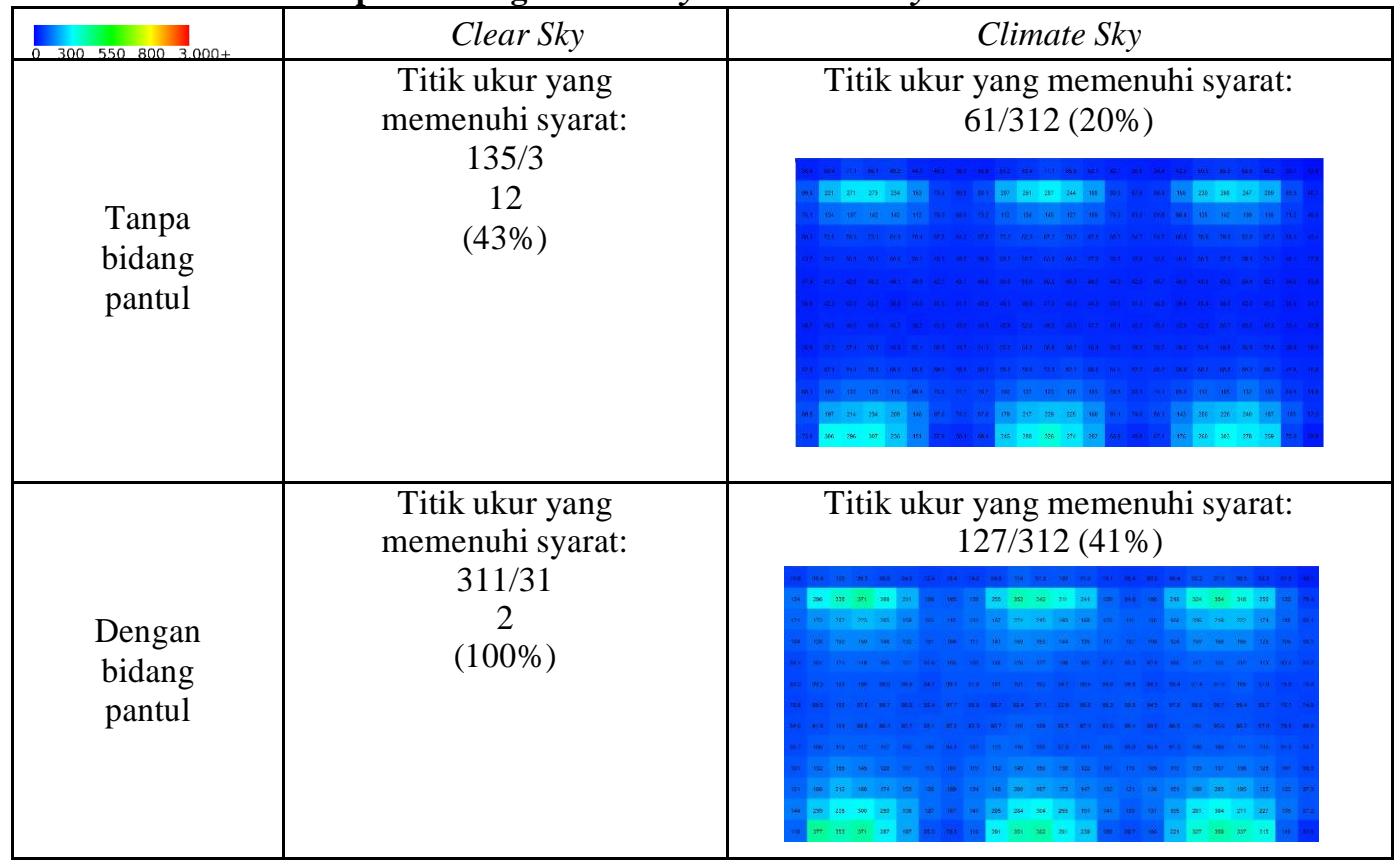

Sumber: Simulasi Lightstanza, 2021

Berdasarkan data hasil simulasi, dapat dilihat bahwa pada bulan dan jam yang sama, pada kondisi clear sky, terlihat bahwa dengan penggunaan bidang pantul pada light shaft, jumlah titik yang memenuhi standar iluminasi dapat meningkat dari $43 \%$ hingga mendekati $100 \%$, dengan itu menambah tingkat pencahayaan sebanyak 2.3 kali lipat. Di sisi lain, pada hasil pengukuran climate sky, ditemukan bahwa dengan penggunaan bidang pantul, titik ukur yang memenuhi syarat dapat meningkat dari $20 \%$ hingga $41 \%$, dengan penambahan tingkat pencahayaan sebanyak 2.1 kali 
lipat dibandingkan light shaft tanpa bidang pantul, menunjukkan rasio penambahan kuantitas cahaya yang tidak jauh berbeda dari clear sky. Namun, jumlah titik ukur yang memenuhi syarat pada pengukuran dengan climate sky hanya mencapai sekitar $40 \%$ dibandingkan tingkat yang terdapat pada pengukuran dengan clear sky.

Berdasarkan analisis di atas, dapat disimpulkan bahwa penggunaan daylight mirror shaft pada climate sky memiliki tantangan yang lebih tinggi karena tingkat intensitas matahari yang pada dasarnya lebih rendah dibandingkan clear sky. Namun, efektivitas penambahan tingkat pencahayaan dengan penggunaan bidang pantul tetap terbukti, dimana rasionya pada climate sky dan clear sky tidak jauh berbeda. Dengan demikian, parameter rasio untuk luasan light shaft pada kondisi climate sky tidak dapat disamakan dengan parameter yang digunakan pada kondisi clear sky.

\section{Analisis Pengaruh Orientasi Bukaan dan Penempatan Light Shaft terhadap Efektivitas Kinerja Daylight Mirror Shaft}

Pada analisis ini, dilakukan pengukuran pada kedua modul objek studi, yakni modul ruang dengan light shaft pada sisi lebar dan light shaft pada sisi panjang ruang, pada dua keadaan orientasi bukaan, yaitu barattimur dan utara-selatan. Pengukuran dilakukan pada bulan Maret, Juni, dan Desember, masing-masing pada jam 09:00, 12:00, dan 15:00. Dari hasil simulasi melalui software Lightstanza, didapatkan hasil jumlah titik ukur yang memenuhi syarat iluminasi pada masing-masing objek, sebagaimana tabel berikut:

Tabel 4. Hasil simulasi pengaruh orientasi bukaan dan penempatan light shaft

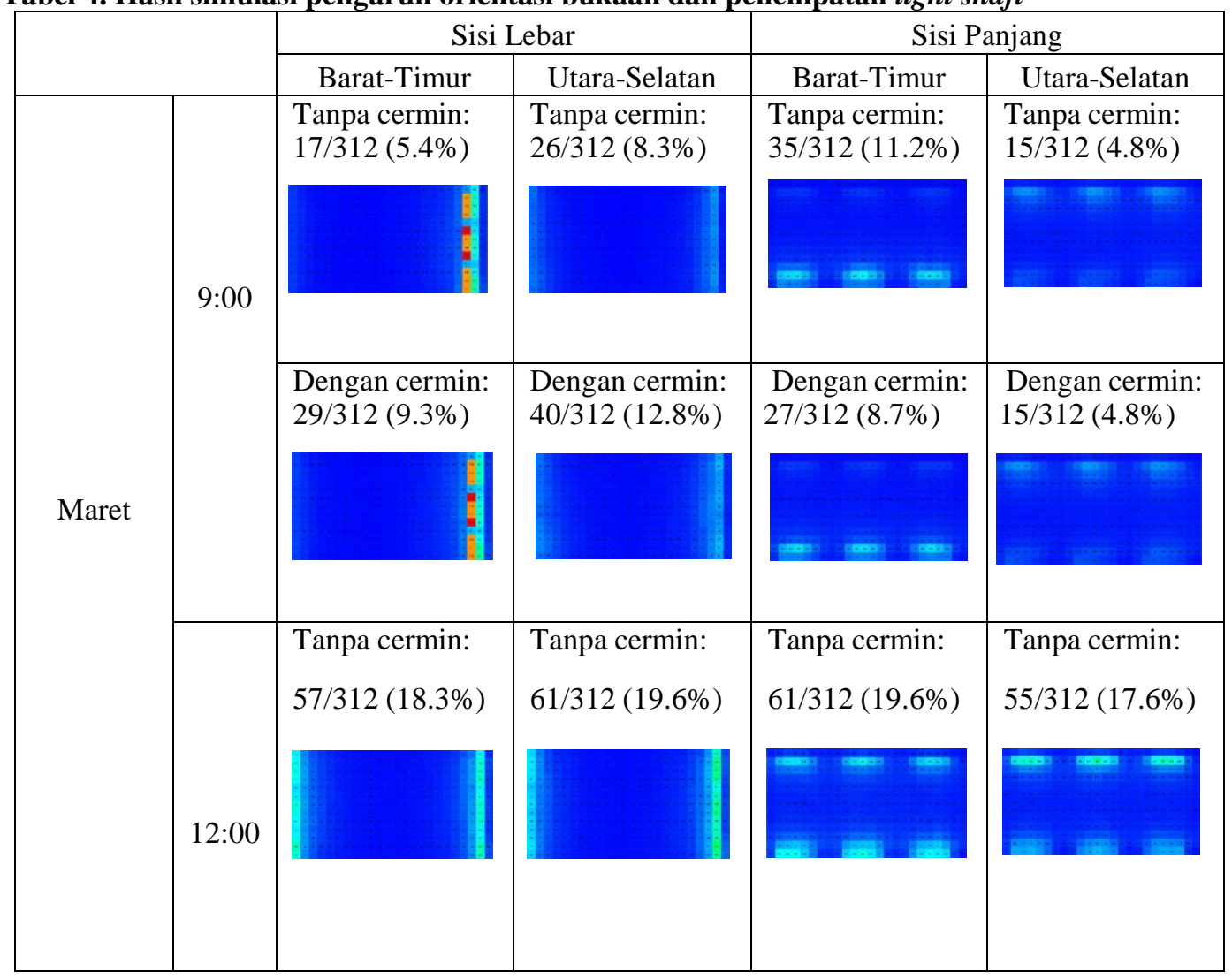




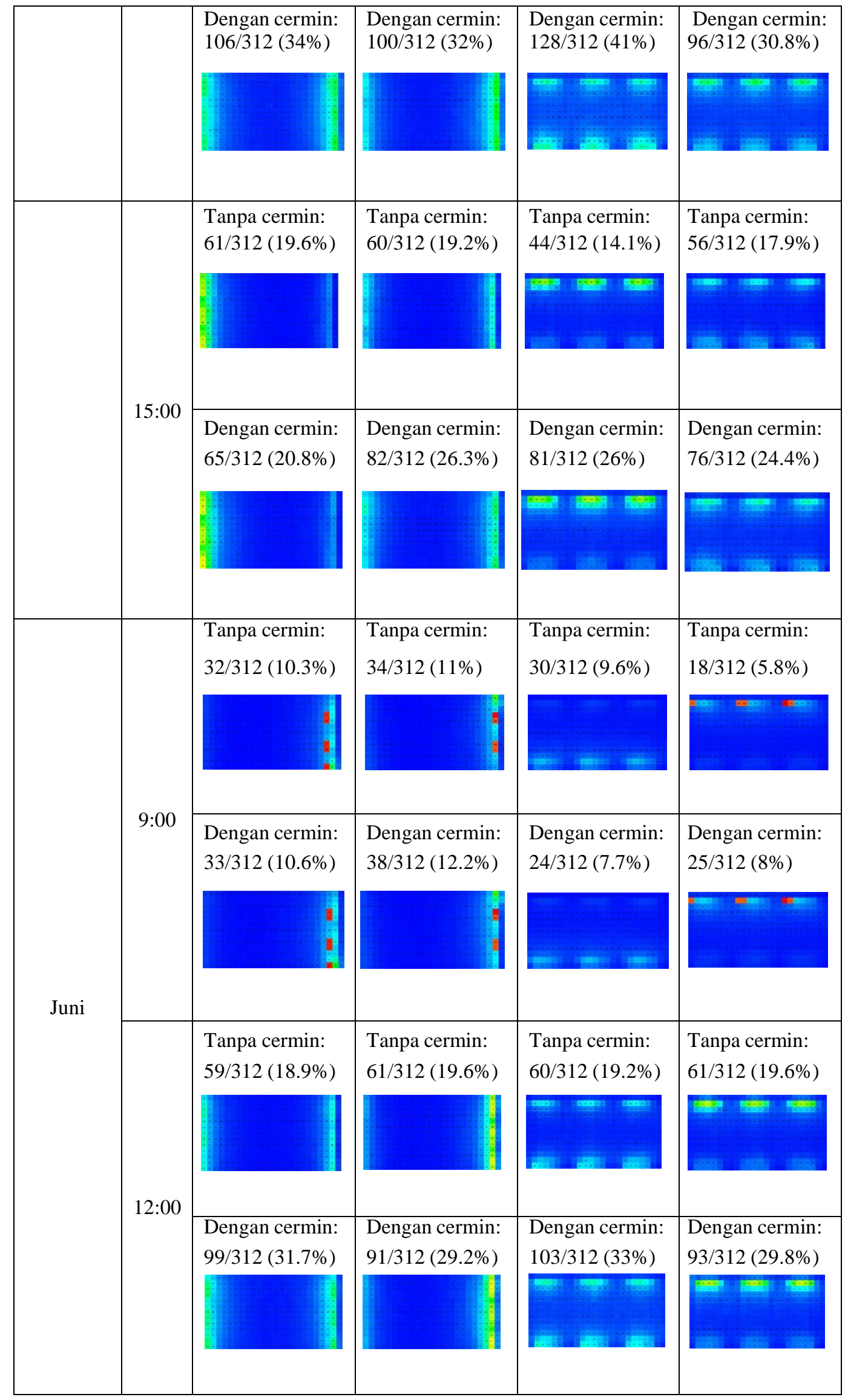


Adella, Efektivitas Daylight Mirror Shaft sebagai Sistem Pencahayaan Alami...

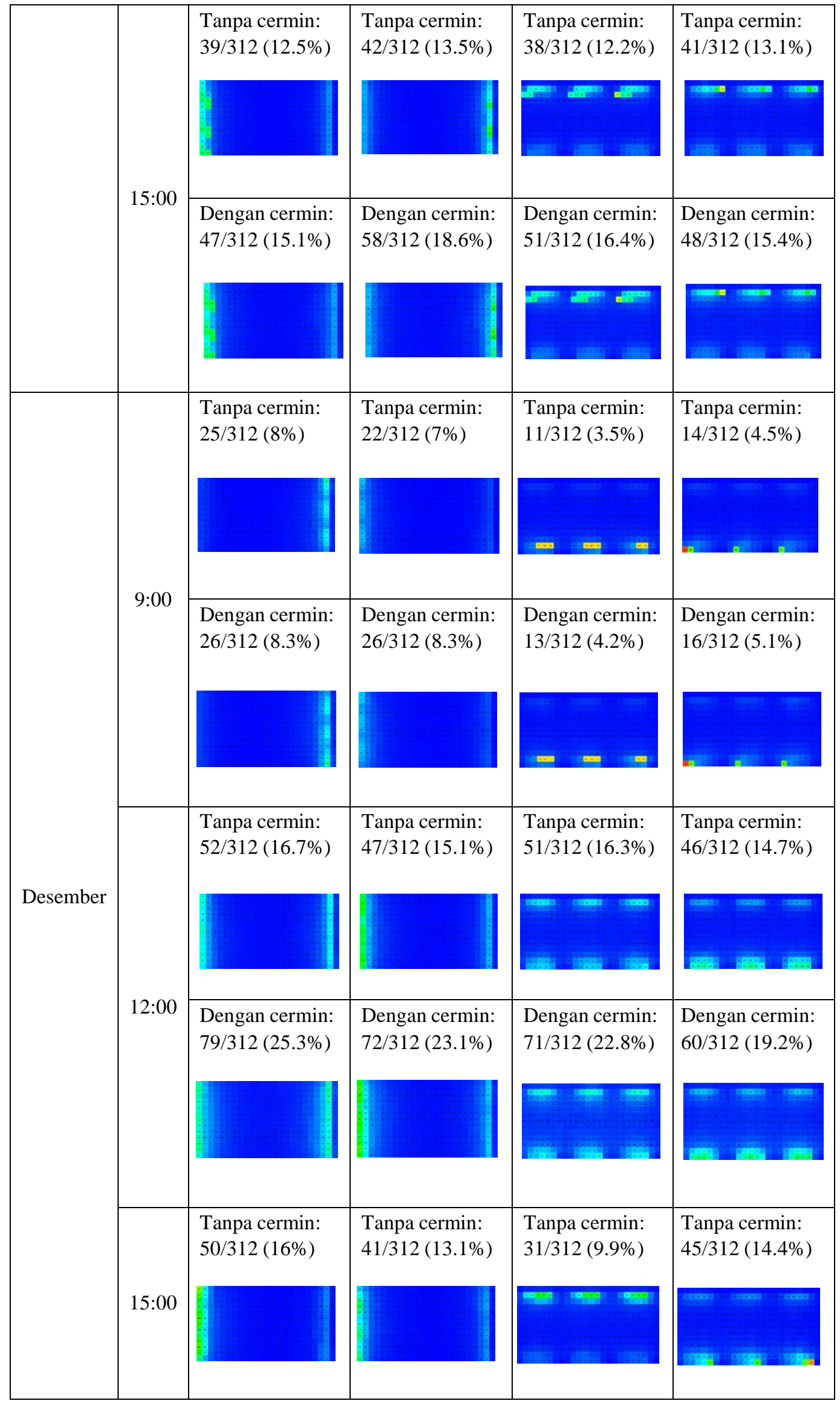




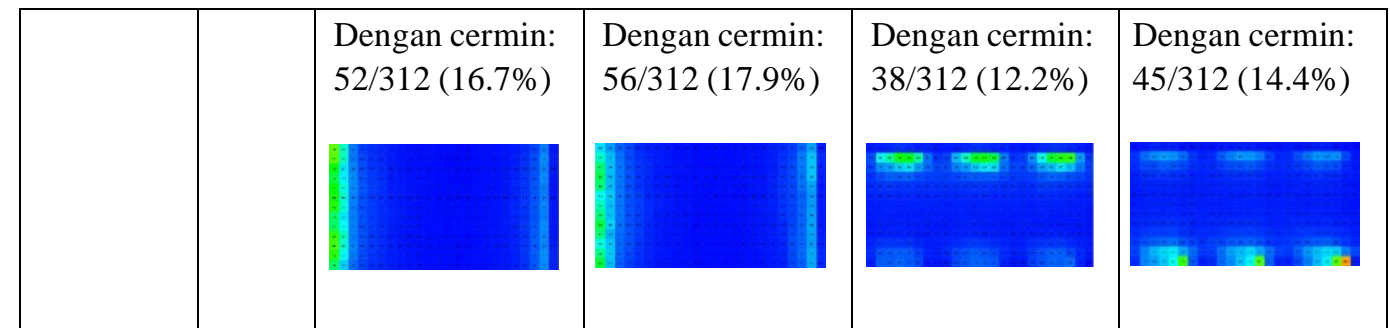

Sumber: Simulasi Lightstanza, 2021

Untuk merangkum data hasil simulasi di atas, dibuat tabel yang menggambarkan rasio efektivitas penggunaan bidang pantul (cermin) pada shaft dibandingkan kondisi tanpa penggunaan bidang pantul.
Angka rasio tersebut didapat dari pembagian angka hasil 'dengan cermin' dengan 'tanpa cermin'. Data tersebut kemudian dibuat dalam bentuk grafik untuk memudahkan analisis.

Tabel 5. Rasio efektivitas penggunaan prinsip sistem daylight mirror shaft

\begin{tabular}{|l|c|c|c|c|}
\hline & $\begin{array}{c}\text { Sisi Lebar - } \\
\text { Barat-Timur }\end{array}$ & $\begin{array}{c}\text { Sisi Lebar - } \\
\text { Utara-Selatan }\end{array}$ & $\begin{array}{c}\text { Sisi Panjang - } \\
\text { Barat-Timur }\end{array}$ & $\begin{array}{c}\text { Sisi Panjang - } \\
\text { Utara-Selatan }\end{array}$ \\
\hline Maret 9:00 & 1.71 & 1.54 & 0.77 & 1 \\
\hline Maret 12:00 & 1.86 & 1.64 & 2.08 & 1.75 \\
\hline Maret 15:00 & 1.07 & 1.37 & 1.84 & 1.36 \\
\hline Juni 9:00 & 1.03 & 1.12 & 0.80 & 1.39 \\
\hline Juni 12:00 & 1.68 & 1.49 & 1.72 & 1.52 \\
\hline Juni 15:00 & 1.21 & 1.38 & 1.34 & 1.17 \\
\hline Desember 9:00 & 1.04 & 1.18 & 1.18 & 1.14 \\
\hline Desember 12:00 & 1.52 & 1.53 & 1.39 & 1.30 \\
\hline Desember 15:00 & 1.04 & 1.37 & 1.23 & 1 \\
\hline
\end{tabular}

Sumber: Pengolahan data penulis, 2021

Grafik 1. Hasil simulasi pengaruh orientasi bukaan dan penempatan light shaft
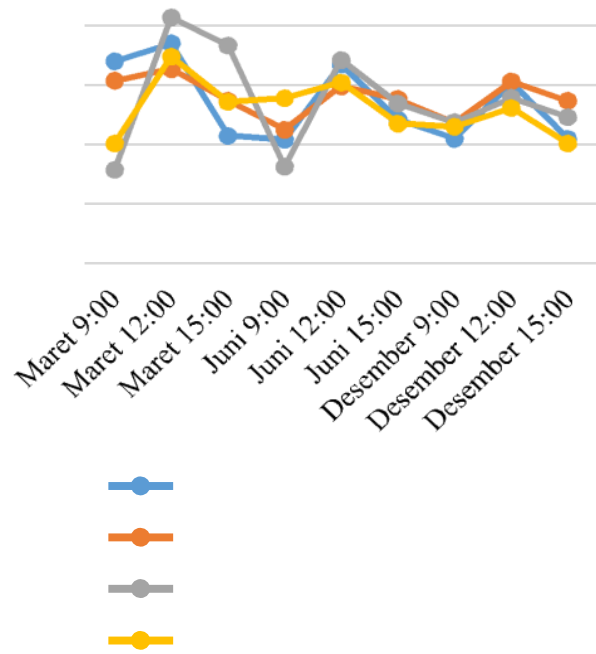

Sumber: Pengolahan data penulis, 2021
Berdasarkan data di atas, dapat dilihat bahwa perbedaan penempatan maupun orientasi shaft tidak menghasilkan perbedaan yang signifikan terhadap jumlah titik ukur yang memenuhi standar iluminasi.

Dari hasil yang didapat, penggunaan bidang pantul pada light shaft mampu meningkatkan jumlah pencahayaan pada ruang sebanyak 1-2 kali lipat, antara menggandakan jumlah pencahayaan atau tidak memberikan efek yang signifikan. Hasil dengan kuantitas pencahayaan yang tertinggi terdapat pada bulan Maret pada jam 12:00. Pada jam tersebut, matahari berada pada posisi tertinggi dan berada pada ekuator. Di sisi lain, terdapat 
hasil data yang menunjukkan kuantitas cahaya dengan cermin yang lebih sedikit dibandingkan hasil tanpa cermin, yakni pada jam 9 bulan Maret dan Juni. Hasil tersebut bukan berarti pengurangan dari segi tingkat iluminasi (Lux) pada titik pengamatan, namun jumlah persebaran cahaya pada ruang. Sebagai hipotesis, hasil tersebut dapat disebabkan oleh pantulan cermin yang bersifat spekular dan tidak merata, sehingga mempengaruhi hasil yang terbaca oleh simulasi pencahayaan. Namun diperlukan studi lanjutan untuk dapat memastikan hal tersebut.

Berdasarkan hasil analisis di atas, ditemukan bahwa penerapan parameter rasio Heliobus ${ }^{\circledR}$ pada kondisi langit tropis tidak dapat menghasilkan pencahayaan yang seoptimal penerapannya pada langit cerah, dimana nilai pencahayaan paling tinggi hanya mencapai $41 \%$ dari total luas ruang. Pencahayaan yang dihasilkan juga kurang merata pada ruang akibat kurangnya pencahayaan untuk menerangi keseluruhan ruang. Hal tersebut menciptakan ruang yang hanya diterangi pada area sekitar bukaan, sehingga dapat timbul kontras antara area sekitar jendela yang terang dengan sisa luasan ruang yang gelap.

\section{Kesimpulan}

Berdasarkan hasil data dan analisis yang telah dilakukan, diambil beberapa kesimpulan, berupa:

1. Pada langit tropis, penerapan prinsip sistem daylight mirror shaft dengan standar dimensi Heliobus ${ }^{\circledR}$ hanya mampu menerangi paling banyak $41 \%$ area ruang dengan standar iluminasi ruang fungsional.

2. Pada langit tropis, penggunaan cermin pada light shaft di ruang bawah tanah tetap dapat meningkatkan besaran luas ruang yang memenuhi standar iluminasi sebanyak 2.1 kali lipat dibandingkan shaft yang tidak menggunakan bidang pantul.

3. Perbedaan penempatan light shaft dan orientasi bukaan tidak berpengaruh secara signifikan terhadap jumlah luasan ruang yang memenuhi standar iluminasi.

Secara keseluruhan, daylight mirror shaft merupakan salah satu strategi pencahayaan yang patut dipertimbangkan dalam rangka memasukkan cahaya ke dalam ruang bawah tanah. Namun, penerapannya di Indonesia masih kurang efektif, karena kurangnya intensitas cahaya matahari pada kondisi langit tropis dibandingkan dengan langit cerah. Dengan demikian, penerapan sistem ini di Indonesia membutuhkan penyesuaian, sehingga menimbulkan banyak potensi untuk diadakan studi lanjutan, agar dapat mengoptimalkan penerapan sistem daylight mirror shaft pada kondisi langit tropis. Saran untuk studi lanjutan mengenai topik ini di antara lain berupa:

1. Mencari parameter rasio luas light shaft terhadap luas ruang berdasarkan kondisi langit tropis (climate sky).

2. Mengembangkan strategi optimasi penggunaan prinsip sistem daylight mirror shaft pada iklim tropis.

3. Melakukan studi terhadap kualitas pencahayaan yang dihasilkan melalui penggunaan daylight mirror shaft.

4. Melakukan studi tentang pengaruh orientasi bukaan Tenggara-Barat Laut dan Timur Laut-Barat Daya terhadap kuantitas pencahayaan. 
Daftar Pustaka

Badan Standarisasi Nasional. (2001). Tata cara perancangan sistem pencahayaan alami pada bangunan gedung. (SNI 032396-2001). Jakarta: Badan Standarisasi Nasional.

Gritsiyenko, D. \& Kasyanov, V. (2017). Solar exposure condition improvement in urban area using light guide. MATEC Web of Conferences, 106, 1-9. DOI http://dx.doi.org/10.1051/matecc onf $/ 201710601015$

Guillemin, A. (2012). Preliminary report on the effect of a heliobus mirror shaft system on daylight in a basement - case study. Available at: https://www.yumpu.com/en/docu ment/view/7287553/preliminaryreport-heliobus-2nd-version.

Heliobus ${ }^{\circledR}$. (no date a). Daylight shaft. Available at: https://heliobus.com/en/products/ da ylight-shaft.

Heliobus $^{\circledR}$. (no date b). Daylight shaft planning aid. Available at: https://heliobus.ch/app/uploads/2 019/05/planning_aid_heliobus_d aylig ht_shaft_en_1216.pdf.

Jain, S. (2017). Incorporating Sunlight in Underground Spaces, International Journal of Engineering Science and Computing, 7(4), pp. 1040010402.

Lechner, N. (2015). Heating, cooling, lighting. New Jersey: John Wiley \& Sons.

Mandala, A., Ritva, A., Gunawan, R. (2016). Komparasi metode perhitungan pencahayaan alami (perhitungan manual, simulasi maket, dan simulasi digital). Bandung: Lembaga Penelitian dan Pengabdian kepada
Masyarakat Universitas Katolik Parahyangan.

Nessim, A.A.I. (2000). Daylighting in underground building. (Tesis S2, Ain Shams University, 2000. Tidak dipublikasikan.

Pangestu, M.D. (2019). Pencahayaan alami dalam bangunan. Bandung: Unpar Press.

Rahim, R., Baharuddin and Mulyadi, R. (2004). Classification of daylight and radiation data into three sky conditions by cloud ratio and sunshine duration. Energy and Buildings, 36(7), 660-666.

DOI https://doi.org/10.1016/j.enbuild. 2004.01.012. 